\title{
A Pilot Study of Online Group Leadership Skills: Perceived Usage and Difficulty Level
}

\author{
Courtney M. Holmes ${ }^{1}$ \\ Virginia Commonwealth University, Richmond, Virginia, United States \\ Kelly A. Kozlowski \\ Walden University, Minneapolis, Minnesota, United States
}

\begin{abstract}
Online counseling service delivery is increasing in frequency and one such modality is online group work. As such, research needs to thoroughly investigate the utility of online groups, including leadership training, skills, and experiences within online groups. This pilot study investigated the perceptions of applied group counseling skills among nine master's-level counseling students as they led online groups for at-risk virtual high school students. The findings indicated different types of skills were considered easy, difficult, or not used by a majority of participants, bighlighting the disconnection between face-to-face and online group leadership skill development and understanding. Implications for counselor education are discussed.
\end{abstract}

Keywords: online counseling, videoconferencing group counseling, at-risk high school students, counseling skills, counselor education

The use of online modalities continues to gain momentum in the field of counseling (Anthony, 2015; Barak, Hen, Boniel-Nissim, \& Shapira, 2008; Richards \& Vigano, 2013). Counselors currently utilize a wide variety of digital modalities such as synchronous chat-based communication, videoconferencing, and email to enhance communication and service provision to clients (Barak et al., 2008). The American Counseling Association (ACA) updated the Code of Ethics (2014) to include directives regarding this shift as it states, "Counselors understand that the profession of counseling may no longer be limited to in-person, face-to-face interactions" (p. 17). Following suit, the

\footnotetext{
1 Address correspondence to Courtney M. Holmes, Department of Rehabilitation Counseling, Virginia Commonwealth University; PO Box 980330,730 E. Broad St, Richmond, VA 23219-1861.Email: cmholmes@vcu.edu
} 
most recent training standards set forth by the Council for Accreditation of Counseling and Related Educational Programs (CACREP, 2016) infused several learning standards related to the need for instruction on technology, mandating that all students must: understand technology's impact on the profession (p. 9); understand ethical and culturally relevant strategies for establishing and maintaining in-person and technologyassisted relationships (p. 10); and understand the impact of technology on the counseling process (p. 10).

This national movement toward the acceptance and infusion of technology into the counseling process must be met with research and data-informed evidence. Thus far, research on the wide variety of types of online counseling is promising and, overall, validates online counseling as a viable service modality (Barak et al., 2008; Richards \& Vigano, 2013). To date, much investigation has focused on the provision of online individual counseling services (Menon \& Rubin, 2011). However, the speed at which the field of online counseling is growing is disconcerting as the training required to manage such changes is lacking (Anthony, 2015). The technology that clients use to communicate and the online environments in which they inhabit are constantly evolving. These changes require the counseling profession to continually adjust; however, current counselor training has not yet adequately evolved to accommodate such changes (Anthony, 2015). Additionally, little information exists regarding the experiences and perceptions of counselors who are providing online counseling, particularly related to the transferability of traditional (e.g., face-to-face) counseling skill sets and techniques. More research needs to be done on the process of online counseling (Dowling \& Rickwood, 2014) including counselors' skill development and their delivery of therapeutic interventions.

\section{Online Counseling Skills}

Over the last decade, counselors have utilized online counseling skills in their relationships with individuals, couples, families, and groups across a variety of service types to include: chat-based, email, and videoconferencing. Online counseling can serve as both a standalone modality as well as a supplementary modality used in conjunction with face-to-face counseling services (Abbot, Klein, \& Ciechomski, 2005; Barak et al., 2008; Mallen, Vogel, \& Rochlen, 2005; Richards \& Vigano, 2013). Castelnuovo, Gaggioli, Mantovani, and Ravi (2003) suggested that a counselor could translate basic techniques such as cognitive restructuring and processing of feelings through a technological medium although a lack of data exists to fully support that claim. In fact, some data imply that simply incorporating traditional techniques into online sessions does not allow for the translation of necessary therapeutic factors (Holmes \& Kozlowski, 2015; Kozlowski \& Holmes, 2014).

As such, the growth in online counseling has spurred the need for online-specific counseling skills to be developed in order to supplement and enhance traditional counseling skills in a digital environment. These skills and techniques can aid counselors in developing interventions and communication methods that are tailored to the 
online environment. One of the main differences between face-to-face and online counseling is the difference in non-verbal communication and physical connection between client and counselor (Barak, Klein, \& Proudfoot, 2009). In order to bridge this particular deficit or difference, specific communication techniques have been developed for text-based online counseling services.

Text-based techniques. Text-based online counseling services are offered in multiple formats including email exchanges or synchronous chat-based services where client and counselor are online and dialoging through text simultaneously. In a survey completed with 14 counseling practitioners, Menon and Rubin (2011) found that email and synchronous chat were the first and second most preferred modality for online counseling, respectively. However, the authors found that videoconference was used by over half of the participants, highlighting that this modality is also heavily employed.

Given the complete lack of non-verbal cues in text-based communication, this modality requires particular skills to convey communication components that are left out. One such technique is termed emotional bracketing (i.e., the use of brackets to express inner thoughts and feelings) which helps to convey feeling and meaning in text-only communication (Barak et al., 2009; Fang et al., 2013). Another technique, descriptive immediacy, entails the conveyance of "descriptive language that provides the client with information about the practitioner's context and actual or imagined nonverbal behaviors toward the client" (Fang et al., 2013, p. 82). Descriptive immediacy is used when a counselor would like to more deeply and thoroughly express a reaction to something a client has said or an action that she or he would like to take within the session. For example, during an initial text correspondence with a client, a counselor might describe how she or he would like to reach out and shake the client's hand and offer her or him a cup of tea (Collie, Mitchell, \& Murphy, 2000). This technique is similar to how a counselor may use traditional immediacy in face-to-face counseling and is used to illuminate the missing in-person context of text-based relationships.

A third text-based technique that online counselors can implement is the use of common and popular online text-based abbreviations to match client language when appropriate (Trepal, Haberstroh, Duffey, \& Evans, 2007). Trepal et al. (2007) also suggested that intentional use of open-ended questions and reflections are necessary in online counseling and that counselors need to be aware of how to effectively use each skill. Haberstroh (2009) suggested that counselor online responses should communicate warmth and understanding through text. Additionally, it has been suggested that empathy (Mallen, Vogel, \& Rochlen, 2005), positive reinforcement, and encouragement (Abbot, Klein, \& Ciechomski, 2008) are crucial to providing successful online therapy.

Videoconferencing. Videoconference technology is used in a variety of therapeutic settings including individual counseling (King et al., 2014), family counseling (Gilkey, Carey, \& Wade, 2009) and group counseling (Hopps, Pepin, \& Boisvert, 2003; Nevanpera, Keranen, Ukkola, \& Laitinen, 2015). Research surrounding the efficacy of this modality is increasing (King et al., 2014; Nevanpera et al., 2015; Simpson, 2009) and showing positive outcomes; however, little inquiry has been placed on particular skills that are useful in sessions. Videoconferencing allows for more immediate connection, 
or social presence, to be felt between client and counselor as both visual and non-verbal cues are available through communication (Biocca et al., 2003). However, external factors can influence the communication and connection (e.g., slow internet speed, home distractions; Simpson, 2009), which renders the discussion regarding intentional therapeutic skill use a crucial one. This discussion is particularly important when practitioners are providing therapy through a videoconferencing group as increasing the number of participants changes the necessary skill set and compounds the interpersonal relationships and therapeutic context (Holmes \& Kozlowski, 2015; Kozlowski \& Holmes, 2014).

\section{Traditional Counseling Skills in Online Counseling}

In Dowling and Rickwood's (2014) qualitative study on the experiences of 49 clients, ages 16-25, who engaged in counseling through a chat-based communication forum, several themes highlighted the difference in communication between online and face-toface work with clients. Participants in this study discussed that straightforward cognitive behavioral therapy techniques were used the most often, while validating the client experience was an additional critical skill. However, the authors did not identify other individual counseling skills that were used within the sessions.

In another qualitative study by Haberstroh, Parr, Bradley, Morgan-Flemming, and Gee (2008), six master's-level students' provided text-based, individual counseling to other students. The authors described a theme wherein participants felt limited in their counseling connection with clients due to the lack of non-verbal cues and face-to-face connection. However, participants in this study stated they believed as though they could translate learned traditional counseling skills to a text-only environment. As with the previously discussed study by Dowling and Rickwood (2014), this study did not examine specific counseling skills and their perceived usefulness in this context. Additionally, these studies focused on text-only communication between a single client and counselor and did not investigate a videoconference or group experience. To date, no studies have been shown to specifically focus on the translation of particular counseling skills to either a chat-based or videoconference group environment.

\section{Group Counseling Skills}

Group work is a specialized area of counseling and requires particular training and intentional coursework in master's-level training programs (CACREP, 2016). Adding multiple members to a therapeutic process inherently changes the therapeutic process. As such, counselors learn particular counseling skills that pertain solely to facilitating groups (Corey, Corey, \& Corey, 2014). For example, in individual counseling a counselor works one-on-one with a client to build a therapeutic relationship and support her or him in intrapersonal development and growth. In group counseling, a slight shift occurs wherein a counselor works to connect members in interpersonal growth and connection with other members (e.g., linking members to one another, 
creating interpersonal process; Corey et al., 2014; Yalom \& Leszcz, 2005). This shift in focus dictates a shift in skill development, as counselors must use techniques to link members through their experiences as well as manage multiple personalities in a room, all while creating a therapeutic environment.

Transferability of traditional counseling skills in online group contexts. Holmes and Kozlowski (2015) and Kozlowski and Holmes (2014) suggested that traditional counseling techniques do not automatically transfer to an online group counseling environment In both studies, results showed that master's-level counseling students in videoconferencing group leadership positions expressed difficulty providing effective therapeutic interventions in an online group as well as an inability to fully utilize process-oriented counseling techniques. Participants in Kozlowski and Holmes' (2014) study stated that they perceived their roles to be less therapeutic and more "teacher-like" wherein the leaders felt responsible for calling on each member individually to participate and answer a specific question. Other themes that emerged were the perception of an artificial feel to the group environment as well as a perception of superficial engagement among the group members and leader (Kozlowski \& Holmes, 2014). More research is needed regarding the transferability of skills in videoconferencing groups.

\section{Training of Online Counseling}

The need for contemporary counselor trainees to be trained in distance counseling techniques has been discussed (Cardenas, Serrano, Flores, \& De la Rosa, 2008; Gilkey et al. 2009; Holmes \& Kozlowski, 2015; Kozlowski \& Holmes, 2014; Simpson, 2009). However, providing online counseling training is in a stage of relative infancy and most traditional counseling training has not yet moved to incorporate online counseling skills or interventions (Anthony, 2015). In Finn and Barak's (2010) survey of 93 counseling practitioners (participants had at least a master's degree), the authors found that the majority of respondents $(94 \%)$ reported that their professional training programs did not include information regarding online counseling.

Currently, little is known about how to train counseling students in the delivery of online counseling (Kozlowski \& Holmes, 2014), particularly group counseling (Kit, Wong, D'Rozario, \& Teo, 2014). It is important that training begins to modernize to include online counseling culture, as well as how theories and behaviors can be applied and understood in an online environment (Anthony, 2015). Given the directives to include technology-driven counseling into training programs (CACREP, 2016), counselor education programs must continue to devise ways in which experiential learning of online counseling can be provided. As experiential learning and practice are documented ways in which counselor education programs train students to develop as group counselors (CACREP, 2016; Steen, Bauman, \& Smith, 2008), the current study incorporated an experiential learning component in internship to provide school counseling master's students the opportunity to provide videoconferencing group counseling to at-risk high school students enrolled in a virtual high school. 


\section{Virtual Education}

A virtual school is defined as an "educational organization that offers $\mathrm{K}-12$ courses through Internet or Web-based methods" (Clark, 2001, p. 1). These schools can be public, private, and for-profit types of institutions (Molnar, 2013). Additionally, students can be involved in online learning programs to different degrees ranging from a part-time, hybrid model in which they take some components of their education in a face-to-face environment and some in a fully digital environment, to fully online programs and degrees. Many states have approved virtual academies to suffice as statefunded educational environments; data have shown that in 2013, 311 fully online K-12 schools were operating in the Unites States and enrolled nearly 200,000 students (Molnar, 2013). The current study collaborated with a fully online, Midwestern high school wherein all students communicated remotely. The groups were offered under the umbrella of the school counseling office and were targeted to reach students at risk of academic probation or dismissal.

\section{The Current Study}

As demonstrated by current literature, counselor educators cannot expect traditional, face-to-face counseling skills to immediately transfer to an online environment without intentional training (Anthony, 2015; Holmes \& Kozlowski, 2015; Kozlowski \& Holmes, 2014). In order to effectively train counselors in the provision of online counseling, more information must be uncovered regarding the transferability and usefulness of traditional counseling skills in online counseling work, as well as the perceptions of counselors who are providing online counseling. To address this gap, the purpose of this pilot study was to examine the perceptions of usage and difficulty level of applied group counseling skills through a collaborative project in which master's-level school counseling students completed a component of their internship providing videoconferencing group counseling to virtual high school students who were at risk of dropping out.

\section{Method}

This study took place within the context of a collaborative project between a CACREPaccredited master's counseling program and a state-approved, online, virtual high school in the Midwest. The internship supervisor in the master's counseling program and several school counselors and administrators at the high school worked together to develop a collaborative approach to provide group counseling services to at-risk virtual high school students. This collaboration began in the summer of 2014 and agreements, contracts, and other documents were developed. The mutual collaboration met the following needs: (a) school counseling master's students enrolled in their Internship course received experiential training and supervision leading online groups for high 
school students and (b) at-risk high school students (e.g., who received two failing grades in the last semester) participated in an eight-week counseling group geared toward academic and personal support.

Several trainings, described below, were mandatory for the master's-level counseling students including an introduction to online group counseling and how to manage the virtual school performance platform, Blackboard Connect. Blackboard Connect (2016) is a digital platform that connects users through chat and video-based communication. This type of platform allows virtual schools to digitally replicate a classroom experience for virtual students. For the group counseling experience, all high school students and the group leader logged in and were simultaneously connected in a single digital space. All high school student group members were recruited in the virtual high school by the school counselor and provided one-quarter of a class credit for their participation.

Overall, the group's focus pertained specifically to academic achievement through a combination of psychoeducation and interpersonal process. The interpersonal component of the group was included to lessen the isolation felt by virtual school students (Sorensen, 2012) and to facilitate the therapeutic factors of group including cohesiveness, universality, and interpersonal learning (Corey et al., 2014). The weekly group session topics, in order of delivery, were as follows: (1) introduction, welcome, and individual goal setting; (2) furthering goal setting and becoming aware of decisionmaking process; (3) staying motivated to accomplish tasks; (4) understanding distractions and challenges with accomplishing goals; (5) understanding personality type; (6) connecting personality type with goal accomplishment; (7) understanding choices and how they are made; and (8) termination. Each session started with a "log on" activity for students to participate in while other members were joining the group, an opening activity and processing, a main activity and processing, and a closing discussion of the group. For more information about the group curriculum and process, see Holmes and Kozlowski (2016).

The online groups met for one hour, once per week, over the course of eight weeks. Each small group self-determined the best day and time to hold the group counseling session. Small groups were led in a Blackboard Connect classroom, which allowed for both group videoconferencing and chat functioning wherein all group members and the leader were connected simultaneously from remote locations. Anecdotal reports provided by group leaders indicated the group members chose to consistently communicate with only the chat function and continually disregarded the opportunity to engage in the group process using the videoconference function, ultimately rendering the communication format chat-based group therapy. Group leaders completed the skills assessment survey at the conclusion of each group session.

\section{Participants}

Group leaders. Upon approval from the Institutional Review Board (IRB), nine school counseling internship students from a CACREP accredited counseling program 
at a Midwestern University agreed to participate. Participants included three men and six women who identified as Caucasian, ranging in age from 24-33 years $(M=25)$. Finally, all participants were in their final semester of clinical training and were graduating at the end of the semester from the university where the study took place.

All participants previously received training in online group counseling and had led at least one online, videoconferencing group under the supervision of an instructor in the Group Counseling course in the master's program. In addition, participants received a three hour training regarding implementing the Blackboard Connect classroom environment used by the school site. After the training, each participant completed an additional four hours of independent, online training focused on building rapport in an online environment, which included specialized tips about using the Blackboard connect environment which was provided by the virtual school. In addition, the school counseling interns completed a three hour training program on how to facilitate online study skills groups. Internship students were each assigned online school counseling supervisors and lead counselors from the virtual school to consult with as-needed and received supervision from the faculty supervisor in weekly group supervision sessions.

Group members. The counseling group members consisted of 72 high school students between grades 9-12 from a state-approved online, virtual school. Parents were notified of the group counseling opportunity and students provided appropriate consent for participation. Each virtual academy high school participant was randomly assigned to one of nine groups each consisting of eight students. Each group was randomly assigned to one internship student who led the group for eight sessions. Students were recruited for participation in the group counseling experience if they had received two grades of $\mathrm{F}$ the semester prior to the implementation of the group. The high school group members were not involved in the current study's data collection or reporting and are described here to contextualize the group membership.

\section{Instruments}

Leadership Skills Questionnaire. The leadership skills questionnaire was developed by the researchers in order to assess the perceived usage and difficulty level of counseling skills that were used by the leaders after each online group session. This questionnaire includes 32-items and is based loosely on the skills discussed by Corey et al. (2014); Jacobs, Schimmel, Masson, and Harvill, (2016); and Yalom and Leszcz (2005) in the seminal group counseling textbooks that define necessary group leadership skills for effective groups. Each skill is attached to a 6-point Likert-type scale including the anchors: Very Difficult, Somewhat Difficult, Neutral, Somewhat Easy, Very Easy, and Not Used. Directions informed participants to identify how easy or difficult each skill was to use during their leadership of the online group. Example skills included: paraphrasing, silence, open-ended questions, encouragers, linking, and creating interpersonal process (see Figure 1 for a complete list of online group counseling skills). Internal consistency for the measure was shown to be high (Chronbach's $a=.94)$. 


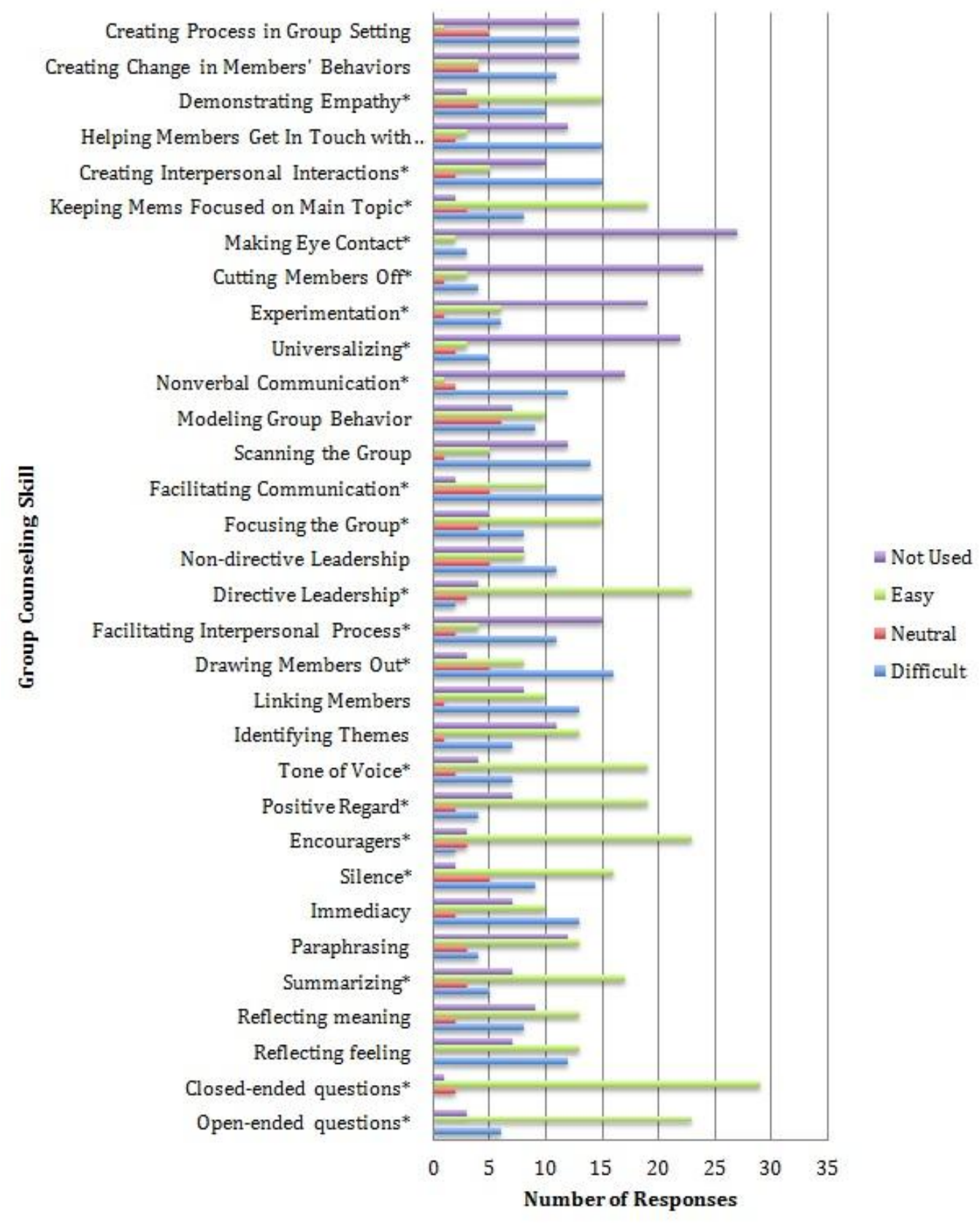

FIGURE1

\section{Online Group Counseling Skills}

Figure 1. Perception of Utilized Group Leadership Skills $(N=32)$ by Master's-level Group Counselors. This figure represents the collected number of responses for each of the skills over the eight-week group. Skills that were identified by participants 15 or more times $(46 \%)$ in a particular way are identified using an asterisk. 


\section{Results}

The researchers analyzed all data using Statistical Package for the Social Sciences v.22 (SPSS) frequencies in order to determine the frequency and percent of participants who marked each skill. The Likert-type scale was divided into six categories: Very Difficult to Use, Somewhat Difficult to Use, Neutral, Somewhat Easy to Use, and Very Easy to Use, and Not Used. For the purposes of data reporting, the anchor options were combined to produce four categories of Difficult, Nentral, Easy, or Not Used. Leaders completed the leadership skill questionnaire after each of the eight group sessions. Of these eight total sessions, three participants completed one or two weekly questionnaires, two participants completed three weekly questionnaires, and four participants completed over four weekly questionnaires after they led the group sessions.

A total of 32 data entries existed for this set compiled of recurring entries from nine total participants over the course of an eight-week group and the data were analyzed as a total set of 32 entries (see Figure 1). The summary of data is designed to showcase the overall perception of the ease of usage within group counseling sessions. Skills that were identified by participants 15 or more times $(46 \%)$ in a particular way are identified within the figure.

Eleven skills were marked as "very easy" or "somewhat easy" to use $46 \%$ or more of the time. These skills included: directive leadership, encouragers, closed-ended questions, open-ended questions, use of tone/voice, summarizing, silence, keep members focused on main topic, focusing the group, positive regard, and demonstrating empathy. Four skills were marked "very difficult" or "somewhat difficult" to use $46 \%$ or more of the time: drawing members out, facilitating communication, creating interpersonal interactions, and helping members get in touch with emotions. Finally, six skills were marked as "not used" $46 \%$ or more of the time: facilitate interpersonal process, nonverbal communication, universalizing, experimentation, cutting members off, and making eye contact.

\section{Discussion}

Through a collaborative project in which master's-level school counseling students completed a component of their internship providing group counseling to at-risk high school students enrolled in a virtual high school, the purpose of this pilot study was to examine master-level school counselors' perceptions of usage and difficulty level of applied group counseling skills. The findings indicate different types of skills were considered easy, difficult, or not used by a majority of participants, highlighting the disconnection between face-to-face and online group leadership skill development and understanding. The findings and implications for the counseling field are discussed below. 


\section{Skills Perceived as "Easy to Use"}

Overall, the skills that participants perceived as "easy to use" included more directive and straightforward clinical skills such as: directive leadership, encouragers, closed-ended questions, open-ended questions, use of tone/voice, summarizing, silence, keeping members focused on main topic, focusing the group, positive regard, and demonstrating empathy. The perception of these particular skills as easier to use correspond with prior research stating that empathy (Mallen et al., 2005), positive reinforcement, encouragement (Abbot et al., 2008), warmth, understanding (Haberstroh, 2009), and validation (Dowling \& Rickwood, 2014) were not only important to the therapeutic process, but also seemingly easy to translate into an online counseling environment. Haberstroh et al. (2008) discussed the experiences of their participants who agreed that they were able to translate general counseling skills into text-based online sessions. The current data highlight the notion that online counselors-in-training perceive that some traditional counseling skills are easily adaptable to an online counseling environment. Interestingly, the skills perceived as easy to use seem to correspond to individual counseling skills that are not specific to a group counseling leadership experience. For example, encouragers, open- and closed-ended questions, focusing, summarizing, positive regard, and empathy are skills that can be found in most counseling skills textbooks. However, these skills are not sufficient in running effective and useful counseling groups (Corey et al., 2014).

\section{Skills Perceived as "Difficult to Use" or "Not Used"}

Overall, the skills that participants perceived as "difficult to use" included more advanced group-specific skills such as: drawing members out, facilitating communication, creating interpersonal interactions, and helping members get in touch with emotions. Data show that participants viewed it difficult to infuse interpersonal process oriented skills to support group development. The skills identified as "not used" were similar in nature and included: facilitate interpersonal process, nonverbal communication, universalizing, experimentation, cutting members off, and making eye contact. These data show that participants perceived not using these skills in a group environment, although several are crucial group facilitation skills. It is unclear why these skills were left unused, perhaps participants perceived that some were too advanced for master's-level counseling students to incorporate or the participants did not believe they needed to be used.

The particular skills that were rated as "difficult" or "not used" show an interesting trend regarding group-specific skills used to create interpersonal process. For example, creating interpersonal interactions is a group-specific skill used to connect members to one another and build relationships and trust within the group. Without this crucial group facilitation skill, it is unclear how online group leaders will be able to link members and support interpersonal process and development. Kozlowski and Holmes (2014) found a similar result through qualitative inquiry of videoconferencing group leaders. Their participants noted the linear nature of the group and their inability to 
promote group process. The participants also expressed feeling as though they were responsible for "calling on" each member and asking them to speak in turn. Due to the text-based nature of the group experience, it makes sense that participants stated they did not use nonverbal communication or eye contact. The researchers hypothesize that these data would change if the group process were to take place via videoconferencing.

Universalizing is a therapeutic factor fostered in group counseling to promote the development of interpersonal connection (Yalom \& Leszcz, 2005). Without the incorporation and development of this therapeutic factor, group leaders might be unable to support the creation of an environment where members begin to relate to one another. Additionally, helping members get in touch with emotions was a skill marked as "difficult" by participants. Processing emotionality is a fundamental competency for counselors. Without the perceived skill set to be able to process feelings, online counselors might believe they are truncated in their ability to facilitate process-oriented therapy. This finding is different from a study conducted by Castelnuovo et al. (2003), which indicated that the processing of feelings was a skill that would easily translate between face-to-face and online environments.

To that end, Hopps et al. (2003) noted in their study of chat-based cognitive behavioral therapy participants that "text-based online therapy might be more viable for goaloriented, educational, and problem-solving therapies" (p. 144) given the nature of directive communication. Participants in Kozlowski and Holmes' (2014) study expressed suggestions of a similar nature, that online groups might be better suited toward directive, psychoeducational material rather than interpersonal process-oriented groups. However, it is unclear whether these group process-oriented skills simply cannot be developed or incorporated into online counseling, or if they become learned through training and practice.

\section{Strengths, Limitations, and Recommendations}

The major strength of this study is that the group processes were created in a real world setting. Through the exploration of actual group processes (not simulated or role play experiences), these data can be used to inform comparable settings or work with similar participants for training or clinical purposes. Another strength of this study is that it is the first of its kind to explore the utility of particular traditional counseling skills in an online group environment. With these data, the field can build knowledge and understanding regarding the transferability and utility of traditional counseling skills to online, therapeutic relationships. However, several limitations exist including the self-report nature of the skill measure. The leaders were master's-level counseling students who were trained to run groups in both school and community settings, however a selfreport measure contains innate bias. Also, the measure was self-developed by the researchers and does not have additional validation of psychometric properties. Finally, the current study features a small sample size and participant attrition or non-response. As such, these data constitute a pilot study that warrants replication.

One important contextual factor to note is that this study took place within the 
systemic structure of a virtual school and the results showcase the perspectives of school counselors. Master's-level school and clinical counselors are trained with the same set of learning outcomes and standards (CACREP, 2016). Additionally, school and clinical groups share overlapping goals and recommended leadership processes. However, the current data represent school counseling-focused groups, thereby potentially impacting the generalizability to clinical groups.

The current findings highlight the importance for sustained research into the myriad facets of online counseling. Counseling and other helping professions must determine and execute rigorous examination of the provision of online services for clients as well as determine appropriate professional and skill guidelines for professionals to include in their online practices (Menon \& Rubin, 2011). The majority of researchers have focused on the efficacy and clinical outcomes of online counseling (Barak et al., 2008; Richards \& Vigano, 2013), which consistently showcases data wherein online counseling outcomes are not significantly different than face-to-face outcomes. However, research needs to focus on the modular components of the process of online work (Dowling \& Rickwood, 2014), including skill development.

Future studies should attempt to increase response rates of participants as well as investigate a larger and more diverse participant pool. Further investigation of skill development of online group leaders in order to determine how process-oriented skills can be more consistently infused in online group leadership is also warranted. More research should be done with videoconferencing group leaders to explore the use of nonverbal communication and eye contact in this type of setting as the current study could not evaluate these particular skills. Additionally, research should focus on the utility of online counseling groups to promote a process-oriented environment where curative factors can be developed as current data speculate that perhaps online groups may be more suitable for educational and structured groups (Hopps et al., 2003; Kozlowski \& Holmes, 2014). Furthermore, qualitative inquiry into the perception of online group leaders' skill development, leadership development, and the therapeutic relationship is merited.

\section{Implications for Counseling and Counselor Education}

Online groups are taking place within the counseling profession (Nevanpera et al., 2015). The current data show a preliminary summary of the perception of online group counseling leaders regarding the ease of use of traditional counseling skills in an online environment. The data show differences in the perception of types of skills, highlighting the importance of continued training in this area. On one hand, online group counselors believed that particular counseling skills were easy to incorporate into group counseling sessions. On the other hand, online group counselors either did not use at all or believed skills were difficult to use that pertained specifically to group facilitation and process. These data highlight that practitioners who are interested in incorporating online counseling modalities into their practices should be aware that additional training and specific orientation of skills and digital relationship building might be necessary in 
order to practice competently.

The current findings validate previous knowledge that highlight the continued importance of intentional training and experiential learning in order for counselors to develop a digital skill set (Anthony, 2015; Menon \& Rubin, 2011). Counselor education programs must begin to incorporate technology-assisted counseling content into their curricula (CACREP, 2016) in order to better prepare new professionals for the myriad of clinical possibilities and future client expectations. All counseling students should be exposed to online counseling in their training programs to begin to understand to the complexities of this type of therapeutic delivery. This article provides one example of how to experientially engage counselors-in-training in online group work in an Internship experience. Other relevant examples of how to use the Group Counseling course for online experiential group leadership have been discussed (Kozlowski \& Holmes, in press; Holmes and Kozlowski, 2016). Finally, ethical and legal issues are consistently at the forefront of the digital counseling discussion. The ACA Code of Ethics (2014) addresses issues and challenges that arise from online counseling and integrating technology into counseling practices. Counselor education programs must teach counselors-in-training how to objectively and critically examine these ethical codes so that they can work within them to provide relevant and appropriate services. For example, the Code of Ethics (ACA, 2014) states that "counselors who engage in the use of distance counseling...develop knowledge and skills...” (H.1.a., p. 17). Counseling students must understand that in order to integrate technology into their practices, they must become aware of technical, ethical, and legal considerations. Given the proliferation of technology, students and professionals must understand that familiarity with the personal use of technology does not render them immediately able to integrate technology in a professional format.

\section{Conclusion}

The current pilot study highlighted important findings regarding the perceived usage of group counseling skills in a chat-based, online group environment. Data show that many necessary and important group counseling skills were identified as "difficult to use" or "not used" by group counseling leaders during the span of an eight week group including cutting members off, universalizing, and creating interpersonal interactions. As demonstrated by these findings, we cannot expect traditional, face-to-face counseling skills to immediately transfer to an online environment without intentional training. In order to effectively train counselors in the provision of online counseling, more information must be uncovered regarding traditional counseling skills, the transferability and usefulness in online counseling work, as well as the perceptions of counselors who providing online therapy. As counseling skills and techniques are a critical foundational component of therapy, counselors who are providing online group therapy must be cognizant of challenges to transferring traditionally learned skills into an online environment. 


\section{References}

Abbot, J. M., Klein, B., \& Ciechomski, L. (2008). Best practices in online therapy. Journal of Technology in Human Services, 26(2/4), 360-375. doi:10.1080/15228830802097257

American Counseling Association. (2014). Code of ethics. Retrieved from http:/ / www.counseling.org/resources/aca-code-of-ethics.pdf

Anthony, K. (2015). Training therapists to work effectively online and offline within digital culture. British Journal of Guidance and Counseling, 43(1), 36-42. doi:10.1080/ 03069885.2014.924617

Barak, A., Hen, L., Boniel-Nissim, M., \& Shapira, N. (2008). A comprehensive review and a meta-analysis of the effectiveness of Internet-based psychotherapeutic interventions. Journal of Technology in Human Services, 26(2), 109-160. doi:10.1080/15228830802094429

Barak, A., Klein, B., \& Proudfoot, J. (2009). Defining internet supported therapeutic interventions. Annals of Behavioral Medicine, 38, 4-17. doi:10.1007/s12160-009-9130-7

Biocca, F., Harms, C., \& Burgoon, J. K. (2003). Toward a more robust theory and measure of social presence: Review and suggested criteria. Presence, 12(5), 456-480. doi:10.1162/105474603322761270

Blackboard Connect. (2016). Blackboard Connect: K-12. Retrieved from http://www.blackboard.com/k12/index.aspx

Cardenas, G., Serrano, B., Flores, L. A., \& De la Rosa, A. (2008). Etherapy: A training program for development of clinical skills in distance psychotherapy. Journal of Technology in Human Services, 26(2-4), 470-483. doi:10.1080=15228

Castelnuovo, G., Gaggioli, A., Mantovani, F., \& Ravi, G. (2003). New and old tools in psychotherapy: The use of technology for the integration of traditional clinical treatments. Psychotherapy: Theory, Research, Practice, Training, 40(1/2), 33-44. doi:10.1037/0033$3204.40 .1 / 2.33$

Clark, T. (2001). Virtual schools: Trends and issues. Phoenix, AZ: WestEd/Distance Learning Resource Network. Retrieved from https://www.wested.org/online_pubs/ virtualschools.pdf

Collie, K., Mitchell, D., \& Murphy, L. (2000). Skills for on-line counseling: Maximum impact at minimum bandwidth. In J. W. Bloom \& G. R. Walz (Eds.), Cybercounseling and cyberlearning: Strategies and resources for the millennium (pp. 219-236). Alexandria, VA: American Counseling Association.

Corey, M. S., Corey, G., \& Corey, C. (2014). Groups: Process and practice (9th ed.). Cengage Learning, Belmont: CA.

Council for Accreditation of Counseling and Related Educational Programs. (2015). 2016 CACREP standards. Retrieved from http://www.cacrep.org/wp- content/uploads/2012/10/2016-CACREP-Standards.pdf 
Dowling, M. J., \& Rickwood, D. J. (2014). Experiences of counsellors providing online chat counselling to young people. Australian Journal of Guidance and Counselling, 24(2), 183 196. doi:10.1017/jgc.2013.28

Fang, L., Bogo, M., Faye, M., Murphy, L., Gibson, M. F., Griffiths, V., ... Regehr, G. (2013). Development and initial evaluation of the cyber-counseling objective structured clinical examination (COSCE). Research on Social Work Practice, 23(1), 81-94. doi:10.1177/1049731512459966

Finn, J., \& Barak, A. (2010). A descriptive study of e-counsellor attitudes, ethics, and practice. Counselling and Psychotherapy Research, 10(4), 268-277. doi:10.1080/ 14733140903380847

Gilkey, S. L., Carey, J., \& Wade, S. L. (2009). Families in crisis: Considerations for the use of web-based treatment models in family therapy. Families in Society: The Journal of Contemporary Social Services, 90(1), 37-45. doi:10.1606=1044-3894.3843

Haberstroh, S. (2009). Strategies and resources for conducting online counseling. Journal of Professional Counseling, 37(2), 1-20.

Haberstroh, S., Parr, G., Bradley, L., Morgan-Fleming, B., \& Gee, R. (2008). Facilitating online counseling: Perspectives from counselors in training. The Journal of Counseling and Development, 86, 460-471. doi:10.1002/j.1556-6678.2008.tb00534.x

Holmes, C. M., \& Kozlowski, K. A. (2015). A preliminary comparison of online and faceto-face process groups. Journal of Technology in Human Services, 33(3), 241-262. doi:10.1080/15228835.2015.1038376

Holmes, C. M., \& Kozlowski, K. A. (2016). Group counseling collaboration model: Support for virtual high school students. Vistas, article 60, 1-12. Retrieved from http://www.counseling.org/docs/default-source/vistas/article_ 6060f227f16116603abcacff0000bee5e7.pdf?sfvrsn=4

Hopps, S. L., Pepin, M., \& Boisvert, J. (2003). The effectiveness of cognitive-behavioral group therapy for loneliness via inter-relay-chat among people with physical disabilities. Psychotherapy: Theory, Research, Practice, Training, 40(1/2), 136-147. doi:10.1037/ 0033-3204.40.1/2.136

Jacobs, E. E., Schimmel, C. J., Masson, R. L., \& Harvill, R. L. (2016). Group counseling: Strategies and skills (8th ed.). Boston, MA: Cengage Learning.

King, V. L., Brooner, R. K., Peirce, J. M., Kolodner, K., \& Kidorf, M. S. (2014). A randomized trial of Web-based videoconferencing for substance abuse. Journal of Substance Abuse Treatment, 46, 36-42. doi:10.1016/j.jsat.2013.08.009

Kit, P. L., Wong, S. S., D’Rozario, V., \& Teo, C. T. (2014). Exploratory findings on novice group counselors' initial co-facilitating experiences in in-class support groups with adjunct online support groups. The Journal for Specialists in Group Work, 39(4), 316-344. doi:10.1080/01933922.2014.954737

Kozlowski, K. A., \& Holmes, C. M. (2014). Experiences in online process groups: A qualitative study. The Journal for Specialists in Group Work, 39(4), 276-300. doi:10.1080/ 
01933922.2014 .948235

Kozlowski, K. A., \& Holmes, C. M. (in press). Teaching online group counseling skills in an on-campus group counseling course. Journal of Counselor Preparation and Supervision.

Mallen, M. J., Vogel, D. L., \& Rochlen, A. B. (2005). The practical aspects of online counselling: Ethics, training, technology, and competency. The Counseling Psychologist, 33, 776-818. doi:10.1177/0011000005278625

Menon, G. M., \& Rubin, M. (2011). A survey of online practitioners: Implications for education and practice. Journal of Technology in Human Services, 29, 133-141. doi:10.1080/15228835.2011.595262

Molnar, A. (2013). Virtual schools in the U.S. 2013: Politics, performance, policy, and research evidence. Retrieved from http://nepc.colorado.edu/publication/virtual-schools-annual2013/

Nevanpera, N., Keranen, A., Ukkola, O., \& Laitinen, J. (2015). Effects of group counseling transmitted through videoconferencing on changes in eating behaviors. Journal of Nutrition Education and Behaviors, 47(6), 555-559. doi:10.1016/j.jneb.2015.07.004

Richards, D., \& Vigano, N. (2013). Online counseling: A narrative and critical review of the literature. Journal of Clinical Psychology, 69(9), 994-1011. doi:10.1002/jclp.21974

Simpson, S. (2009). Psychotherapy via videoconferencing: A review. British Journal of Guidance \& Counselling, 37(3), 271-286. doi:10.1080/03069880902957007

Sorensen, C. (2012). Learning online at the K-12 level: A parent/guardian perspective. International Journal of Instructional Media, 39(4), 297-309. doi:10.4018/IJOPCD. 2016040102

Steen, S., Bauman, S., \& Smith, J. (2008). The preparation of professional school counselors for group work. Journal for Specialists in Group Work, 33(3), 253-269. doi:10.1080/01933920802196120

Trepal, H., Haberstroh, H., Duffey, T., \& Evans, M. (2007). Considerations and strategies for teaching online counseling skills: Establishing relationships in cyberspace. Counselor Education \& Supervision, 46, 266-279. doi:10.1002/j.15566978.2007.tb00031.x

Yalom, I., \& Leszcz, M. (2005). Theory and practice of group psychotherapy (5th ed.). Cambridge, MA: Basic Books. 